\title{
Patterns of executing budgeting as a tool of planning and control: with special reference to listed companies in Sri Lanka
}

\author{
Indrani, M. W. ${ }^{1}$, Wickremasinghe.G. ${ }^{2}$ \& Moonsamy Naidoo ${ }^{2}$ \\ ${ }^{1}$ Department of Accounting and Finance, University of Ruhuna, Sri Lanka \\ ${ }^{2}$ Victoria University Business School, Victoria University, Australia
}

\begin{abstract}
In the modern business world,budgets accomplish a significant role both in planning and control of businesses towards attaining organizational goals. The purpose of this study is to investigate patterns of executing budgeting technique by different companies/industry sectors, inrealizingintended purposes. Applying Mixed Method Research (MMR) approach, datafor this study was collected through questionnaire survey and discussions with financial executives of 42 listed companies representingfive sectors. In view of the major types of simultaneous and sequential mixed methods deigns, this research is concerned with two paradigms (out of eight paradigms): $Q U A N+$ qual and $Q U A N \rightarrow$ qual, respectively. The survey data were analyzed using SPSS software and frequency tables while employing 'thematic analysis' and 'content analysis' for descriptive data. It identified 'results point of interface' as the suitable position for integrating core component 'QUAN' and supplemental component 'qual' to provide meaningful interpretations and sound conclusions for the study.

Patterns of application of budgeting vary to a considerable extent from one another within the industry and between industries. Such differences may be largely attributed to the nature of businesses, impact of environmental changes on business activities, markets served (local or foreign), policies, procedures, and specific circumstances that individual companies exercised. Thus, it suggests that these factors may have an impact on the patterns of budgeting practices adopted by individual companies/ industry sectors. Findings conclude that budgeting seems to be the most important technique for all companies irrespective of their sector, playing the biggest role for planning than control of businesses. This study provide helpful insights and useful guidelines to business entities practicing under different organizational contexts and influences, in applying certain MA techniques i.e. budgeting in a proper way making sure that they are moving on to appropriate direction towards achieving organizational goals and hence business sustainability.
\end{abstract}

Keywords - Budgeting, Planning, Control, listed companies, Industry sectors

International Journal of Accounting \& Business Finance - 46 -

Vol.5 Issue 22019 


\section{Introduction}

As the modern business world is highly competitive, business firms must become more competitive on a global basis in order to survive in businesses. Management Accounting (MA) literature thus suggests that effective planning and control are crucial for achieving organizational goals and objectives. Effective planning ensures that goals are selected with care and effective control ensures that the selected plans are implemented appropriately. In this respect, budgets accomplishasignificant role both in planning and control in attaining organizational goals (Herath and Indrani, 2007). TrimisiuTunji (2013) stated that firms seek to adopt the concept of budgeting and budgetary control to satisfy their needs at the least possible costs. It recognizes budgeting as a useful tool that guides firms to evaluate whether their goals and objectives are actualized.

However, Tuanmat and Smith (2011) emphasize that, as the business environment has been changing continuously, it is critical to ensure that an appropriate MA system is practised in organizations. In view of the changing environment in which firms now operate TrimisiuTunji (2013) also indicated that budgets, as a continuous management activity, should adapt to changes in the dynamic business environment. This is important because effective management accounting system (MAS) can help managers to better coordinate business activities and provide useful information for them to make decisions, and this process will ultimately improve organizational performance (Tuanmat \& Smith, 2011). In this respect, Trimisiu Tunji (2013) emphasized that dedicated work force, improved technology and effective policies (budgeting inclusive) help manufacturing companies to remain effective and efficient in fulfilling their stewardship obligations to the stakeholders.

It is generally accepted that 'the social system consists of different sub systems /components each having different characteristics so that if we want to identify those characteristics, we should investigate each sub systems / components separately'. In the sense, it isrealized that businesses may vary from one another within the industry and also between industries, in terms of the nature of products, product diversification, markets served (i.e., domestic or export), market position (market leader or non-leader), length of operations in years, size (large, medium, or small), policies, procedures, objectives and specific circumstances that individual companies face. All of these may have an impact on the extent and patterns of implementing certain MA techniques like budgeting in an organization. 
Thus, this study attempts to investigate patterns of applying budgeting technique by 42 listed companies dealing with different types of businesses under different organiza tional contexts, representing different industry sectors (five) mainly focusing on manufacturing and related sectors. In the sense, the findings of this study will provide helpful insights and useful guidelines to organizations facing with changing business environment and having different characteristics their own, especially those executives who are responsible for making sure that their companies move in an appropriate direction by applying most essential MA techniques such as budgeting in a proper manner.

\section{Research Objectives and Methodology}

\subsection{Research Objectives}

The main objective of this study is to investigate patterns of executing budgeting technique by listed companies representing different industry sectors in the Sri Lankan context, stressing associated similarities and differences among sectors, with regard to purposes of budgeting, frequency of forecasting budgets, bases for formulating budget estimates, necessity and frequency of budget revision, and application of Activity based budgeting (ABB).

\subsection{Methodology}

This study applies a Mixed Method Research (MMR) mainly based on the MMR designs made by Morse (2010).It is vibrant that there are strengths and weaknesses in both quantitative and qualitative research methods, so that one possible reaction to this is to suggest combining them in 'mixed methods research'. Such a strategy would seem to allow the various strengths to be capitalised upon and the weaknesses offset (Bryman \& Bell, 2007). This MMR approach thus supports the researcher in collecting and analyzing both quantitative and qualitative data to acquire meaningful findings, and hence reach sound conclusions.

\subsubsection{Sample and population}

By applying the multi-stage purposeful random sampling technique, the researcher first, purposefully selected five industry sectors representing manufacturing and manufacturingrelated industries,from 20 sectors listed in Colombo Stock Exchange.Because the researcher realized that the practices of these five sectors are more relevant for this study than other sectors such as telecommunications and banking.

As many MMR studies do, then it appliednon-random sampling methods called snowball sampling, convenience sampling and purposeful sampling in selecting the most suitable accessible 
sampled companies from the designated industry sectors. In this sampling process, it considered factors such as accessibility to companies, relevance of businesses of companies to the research area, and nature of data and information required. Snowball sampling is a form of convenience sample, because, with this approach, the researcher makes initial contact with a small group of people relevant to the research topic and then uses these to establish contacts with others (Bryman\& Bell, 2007).

Accordingly, sometimes the researcher could call on other companies through links already established with responding companies who were initially contacted for the same purpose. Convenience sampling denotes choosing individuals who are conveniently available and willing to participate in the survey (Onwuegbuzie \& Collins, 2007). Utilising these sampling methods, the researcher selected 42 appropriate companies representing five industry sectors: Food Beverages \& Tobacco-F \& B (8/22),
Chemicals \& Pharmaceuticals -CHEM (3/12), Diversified Holdings - DVS (5/16), Manufacturing - MNF (18/39), and Plantation- PLT (8/20), accumulating to the population of 109 companies.

\subsubsection{Personnel involved in the survey}

The researcher then contacted suitable respondents giving priority to executive level management i.e. finance manager, deputy general manager (DGM) finance, finance controller, finance director (signifying approximately $80 \%$ of respondents); than the middle level management like management accountants and financial accountants from those companies (see Table 1). This strategy helps maximising understanding on the underlying phenomena while obtaining required data for the study with adequate accuracy and completeness. Because senior manage ment is typically competent to provide more descriptive analytical answers to questions with their vast knowledge and experience.

Table 1. Management personnel involved in the survey

\begin{tabular}{|c|c|c|c|c|c|}
\hline \multirow[b]{2}{*}{ Industry sectors } & \multicolumn{4}{|c|}{ Number of Companies } & \multirow[t]{2}{*}{ Total } \\
\hline & SM & MA & FA & $\mathrm{MA}+\mathrm{FA}$ & \\
\hline $\mathrm{F} \& \mathrm{~B}$ & 5 & 2 & 0 & 1 & 8 \\
\hline CHEM & 0 & 3 & 0 & 0 & 3 \\
\hline DVS & 5 & 0 & 0 & 0 & 5 \\
\hline $\mathrm{MNF}$ & 17 & 0 & 1 & 0 & 18 \\
\hline PLT & 7 & 0 & 0 & 1 & 8 \\
\hline Total & 34 & 5 & 1 & 2 & 42 \\
\hline$\%$ & 81 & 11.9 & 2.4 & 4.8 & 100 \\
\hline
\end{tabular}

Notes: SM-Senior Management; MA-Management Accountant; FA-Financial Accountant; MA+FA both Management Accountant and Financial Accountant 


\subsubsection{Data collection}

Data collection was undertaken using two instruments: questionnaire survey and discussions. In MMR approach, it was intended to obtain more clarification and descriptive information apart from the core data, particularly relating to specific circumstances that individual companies face. It applied a personal visit approach to each and every company in the sample in order to maintain sound response rate $(100 \%)$ and the quality of data obtained. For this purpose, the researcher typically contacted financial executives of companies and, if they were not available, then contacted management accountants/ cost accountants or financial accountants.It also collected secondary data through available sources: policy documents; annual reports; budgets; variance analysis reports; and explored websites of companies for background information before starting company visits.

Deliberating the MMR designs of Morse (2010), for this study, the core component is identified as 'QUAN' and supplemental component as 'qual'. Accordingly, data collection took place in two ways for primary data: i) collecting core data for QUAN, through the survey and ii) collecting supplementary qual data through discussions made concurrently and subsequent to the survey. In view ofthe major types of simultaneous and sequential mixed methods deigns by Morse (2010, p. 341), it seems that this research is concerned with two paradigms (out of eight paradigms) in respect of methods and strategies applied, indicated as: QUAN + qual and QUAN $\rightarrow$ qual, respectively. Here, the theoretical driver is indicated with 'uppercase' and supplemental strategy with 'lowercase'.

i) Collecting core data for QUAN: Before visiting companies, relevant officials of each company were contacted by e-mail or telephone and made relationship with them, andthen sent those questionnaires with a brief summary of research aims. Upon receiving respondents' responses, arrangements were made for appointments with them. Accordingly, the researcher actively participated in and was able to complete the survey of 42 companies by maintaining a $100 \%$ response rate.

ii) Collectings upplementary qual data: This involved discussions with respondents made in two stages: QUAN +qual and QUAN $\rightarrow$ qual. The first stage (QUAN+qual) comprised discussion conducted simultaneously with the same respondents participated in the questionnaire survey. In this stage, 
the researcher spent approximately two hours in each company and filled questionnaires while continuing discussions with respondents. As the respondents were sent the questionnaire in advance, the researcher could have fruitful discussions with officials with a proper understanding of the questions and of anticipated investigations.

In the second stage (QUAN $\rightarrow$ qual), depending on the situations, availability of personnel and information requirements, time constraints/interest of respondents to provide more details; which were identified in the QUAN + qual stage, the researcher conducted further discussions with officials, when required and thus, not all companies were involved. Accordingly, the second stage discussions were made with officials as shown in Table 2. Accordingly, subsequent discussions were conducted with financial executives / accountants, taking advantage of their thorough knowledge and experience on the area of concern.

Table 2. Discussions made with officials of sampled companies subsequent to the Survey

\begin{tabular}{|c|c|c|c|c|}
\hline $\begin{array}{c}\text { Industry } \\
\text { sector }\end{array}$ & $\begin{array}{c}\text { No. of Companies } \\
\text { involved in discussions }\end{array}$ & Respondents & $\begin{array}{l}\text { Time spent } \\
\text { (hours) }\end{array}$ & At what time \\
\hline $\mathrm{F} \& \mathrm{~B}$ & 3 & $\begin{array}{l}\text { Finance controller } \\
\text { Finance director } \\
\text { General Manager } \\
\text { (specialist in finance ) }\end{array}$ & $\begin{array}{l}11 / 2 \\
2 \\
1\end{array}$ & $\begin{array}{l}\text { A } \\
\text { B } \\
\text { B }\end{array}$ \\
\hline CHEM & 1 & Management accountant & $21 / 2$ & $\mathrm{~A}$ \\
\hline DVS & 3 & $\begin{array}{l}\text { Finance manager } \\
\text { Finance manager } \\
\text { Finance director }\end{array}$ & $\begin{array}{l}1 \frac{1 / 4}{2} \\
21 / 2 \\
1\end{array}$ & $\begin{array}{l}\text { A } \\
\text { B } \\
\text { B }\end{array}$ \\
\hline MNF & 5 & $\begin{array}{l}\text { Finance manager } \\
\text { Finance director } \\
\text { DGM Finance } \\
\text { Finance controller } \\
\text { Finance manager }\end{array}$ & $\begin{array}{l}2 \\
11 / 4 \\
1 \\
11 / 2 \\
2\end{array}$ & $\begin{array}{l}\text { B } \\
\text { A } \\
\text { B } \\
\text { A } \\
\text { A }\end{array}$ \\
\hline PLT & 2 & $\begin{array}{l}\text { DGM (Finance) } \\
\text { Finance controller }\end{array}$ & $\begin{array}{c}3 \\
21 / 2\end{array}$ & $\begin{array}{l}\mathrm{B} \\
\mathrm{B}\end{array}$ \\
\hline Total & 14 & & 25 & - \\
\hline
\end{tabular}

Notes: A - same day just after the survey; B- Another day with appointment after the survey 
With these discussions made concurrently and subsequent to the survey, the researcher empowered to obtain, further information with more clarifications and examples, details about specific situations faced by individual companies/ industry sector, that are essential for making expressive complete interpretations and findings and then reaching sound conclusions for the study.

\subsubsection{Data analysis}

The survey data were tabulated and analyzed using SPSS software, and frequency tables while employing 'thematicanalysis and 'content analysis' for descriptive data. According to Morse (2010), two points of interfaces are available in MMR design for integrating core and supplemental components to form a meaningful complete analysis and interpretations: 'analytical point of interface' that concerns with transforming qual data into numerical form; and 'results point of interface' that adding qual data to QUAN results. Of these, the researcher identified 'results point of interface' as the suitable position for integrating core component 'QUAN' and supplemental component 'qual'. Because the qualitative data and information could not be transformed into numerical form, but they are suitable for adding to QUAN results to provide descriptive meaningful complete analysis and interpretations for the study. The researcher was motivated to use MMR approach to the study as it helps produce complete and expressive analysis and thorough interpretation on findings.

\section{Literature review}

In the changing business environment, it is critical to ensure that an appropriate MA system is practised in organizations (Tuanmat and Smith, 2011). Literature review specifies that traditional MA techniques like budgeting is still important as an effective planning and control tool that enable management for improving performance and hence achieving organizational goals and objectives. Abdel-Kader and Luther (2006), demonstratedthat budgeting for planning and controlling costs, product profitability analysis and performance evaluation based on financial measures are shown to receive greatest emphasis, ratifying that traditional MA is very much alive.

In contrast, Sulaiman, Ahmad and Alwi (2004), in a literature review of four Asian countries: Singapore, Malaysia, China and India, suggests that traditional MA techniques, such as traditional budgeting, standard costing and variance analysis seen to be less useful in the present manufacturing environment. Overall, the evidence 
reviewed suggests that the use of contemporary MA tools is lacking, while the use of traditional MA tools remains strong in these four countries (Sulaiman et al., 2004).

Waweru, Hoque \& Uliana (2005), in a survey of listed companies in South Africa presented somewhat different ideas that modern MA techniques such as activity based costing (ABC) and balanced scorecard-type performance measures are used together with the traditional MA techniques, such as budgeting and standard costing. Further, the high emphasis on cost management and the widespread use of flexible budgets for control purposes show that those South African firms are striving to reduce waste in their production processes, and increased use of $\mathrm{ABC}$ and emergence of $(A B B)$ suggest a move towards the elimination of non-value adding activities and hence waste reduction. Contrary to such practice of flexible budgets in South African companies, Abdel-Kader and Luther (2006) found that, in the UK almost all companies use budgeting for planning and control, however, they work only with fixed budgets and thus, a high proportion does not flex or amend their budgets for changes in volumes or other factors.

Chenhall and Langfield-Smith (1998), through a survey in large Australian manufacturing firms, revealed that, financial performance measures such as budgeting for controlling costs, budget variance analysis indicated high adoption rates and showed high benefits. The findings ultimately suggest that financial performance measures continue to be an important aspect of MA; however, these are being supplemented with a variety of nonfinancial measures.

Wijewardena and De Zoysa (1999) revealed that Australian companies place greater emphasis on cost control tools, such as budgeting, standard costing and variance analysis at the manufacturing stage, while Japanese companies devote greater attention to cost planning and cost reduction tools based on target costing at the product planning and design stage. They conclude that budgeting is considered an equally important MA tool for planning and controlling product costs in both countries. Almost all Australian companies prepare budgets such as profit and loss statements, balance sheets, operating budgets, cash budgets and capital expenditure budgets, just like Japanese companies.

But the substantial difference between the two countries is that the balance sheet and capital expenditure budget seems to be less popular in Japan whilst annually prepared budgets are more 
popular in Australia, as opposed to biannually prepared budgets in Japan, Also,monthly budgets is at a moderate level, while quarterly budgets are to be seen less important in both countries. Least importance is given to budget preparation beyond one year, showing 4\% in Japan and 15\% in Australia. But this does not suggest that Japanese companies are not engaging in longterm planning. In relation to preparation of long-term plans, more concentration is given by Japanese companies (95\%) than their Australian counterparts $(83 \%)$.

Onyiah, Ezeamama, Ugwu\&Mgbodile (2016) exploring Ministries, Departments and Agencies in Nigeria suggest that budget is a veritable tool for planning, controlling, communicating, decision making and value creation, stressing the necessity of making efforts to ensure that all agencies tolerate strictly to the Budget Implementation Reform Strategies.In this concern, Segun and Olamide (2009) emphasize that though the budgeting system is not perfect, budgeting is perceived by managers as a useful exercise and a valuecreation process.

Accordingly, empirical evidence induces that budgeting is an absolute tool for planning, controlling, coordinating, communicating, evaluating and improving performance and decision making. On the other hand, some specialists have mounted wideranging criticism of the manner in which budgetary systems are typically implemented, claiming that budgeting is not a worthwhile exercise, no added value to organizations, managers are dissatisfied with it, and therefore it should be abandoned (Segun\&Olamide, 2009). In line with these, Senoo (2018) cited that even though budgeting is at the core of management control systems (MCS), it has been constantly subjected to criticisms. Segun\&Olamide (2009), however, contended that budgeting is perceived by managers as a worthwhile exercise and a value creation process.

Also, companies in Nigeria operate budgets annually, thereby confirming their widespread use. Besides, budgeting is a veritable tool for planning, control, communicating, decision making and value creation. Thus, they recommend that research should be directed towards improving the budgetary system rather than totally abandoning it (Segun \& Olamide 2009). In the sense, as cited by Segun \& Olamide (2009), it is assumed in the literature that budgeting is a veritable tool for effective management (Grifel, 1993; Lucey, 2000; Millar, 1997; Otley, 1978; Schwartz, Nikias, \&, Young, 2008; Yeung, 2006).

Advocates of budgeting further convince that the budgeting process forces a manager to become a better 
administrator and puts planning on the front position of the manager's mind. Meanwhile, many healthy businesses drop down probably because managers could not identify problems in advance or they failed to monitor and adjust budgets to changing conditions (Horngren, Sundem, Stratton, Burgstahler, \&Schatzberg,2008). In view of modern changing business environment, Tuanmat and Smith (2011)also emphasized that it is critical to ensure that an appropriate MA system is practised in organizations. However, considering the changing environment in which firms now operate, Trimisiu Tunji (2013) illustrates that budget, as a continuous management activity, should adapt to changes in the dynamic business environment.

Considering the literature, overall, it evidences that even though budgeting is subjected to criticisms, most companies in different countries adopt budgeting technique as an essential tool for planning and control, but the level and patterns of application and the importance they have given for the technique seem to be different,all of which affect the success or failure of the business. Thus, investigating patterns of budgeting practices is vital for any business entity to identify its strengths and weaknesses and to take measures to improve the practices towards achieving intended purposes.
Libby and Lindsay (2010) stated that, most companies practice budgeting and are aware that it has some influence. Exploring patterns in budgeting practices of North-American organizations, they found that majority of firms continues budgeting system for control purposes and is supposed to be value-added; however, problems exist with budgets, still most companies have no plans to abandon this practice, instead many are planning to take steps to improve their budgeting systems to overcome some of the common criticisms.

Supporting to these arguments, Barasa, Cleary, Molyneux, \& English (2017) based on a case study in public hospitals in Kenya, disclosed that the budgeting and planning process was characterized by lack of alignment, inadequate role clarity and the use of informal prioritysetting criteria. Also, decision making in both hospitals did not result in reallocation of resources. It implies that budget revision was not practiced in these hospitals. Authors suggest that public hospitals in Kenya need to improve their budgeting and planning processes by harmonizing these processes, improving role clarity, using explicit priority setting criteria.

Investigating budgeting patterns of companies listed on Tokyo Stock Exchange, Senoo (2018) classified 
budgeting practices into three patterns: flexible, strategic, and poor budgeting; and identified that these patterns differ from the characteristics of "Japanesestyle" budgeting noted in the literature. Senoo also stated that the types of patterns for control practice linkages in general companies remain unclear.Scott \&Enu-Kwesi (2018) analyzing the role of budgeting in the district assemblies of Ghana towards service delivery, showed that citizens rated service delivery poorly, while district assembly officials rated service delivery as satisfactory. However, the study recognized that budgeting practices had positive significant influence on service delivery.

Further, Sponem and Lambert (2016) identified five patterns of budget practices, each of these clusters displays different budget roles, criticisms and different levels of satisfaction. i) The yardstick budget: assemble both top and operational managers on strategy in the long run, and encourages them to closely follow its deployment in the short run; ii) The coercive budget serves a management by objectives approach; iii) The loose budget is a tool for deploying the strategy; iv) The interactive budget combines management by objectives and strategy deployment.

The indicative budget has no any clearly defined function. Both interactive and coercive budgets are used to evaluate and reward. The interactive budget operates as a central tool to structure negotiations and discusses strategic choices, generating high budget satisfaction and little criticism: it is therefore legitimate to use it for performance evaluation and reward. The coercive budget, on the other hand, does not foster discussion, and is perceived as a tool for sanctioning rather than a useful management tool for monitoring business activity. Moreover, Loose and indicative budgets demonstrate a low level of budget evaluation and weak links between the budget and incentives. Analyzing both these clusters theyadvocated that budget participation and budget flexibility are not sufficient to ensure budget satisfaction (Sponem and Lambert, 2016).

In agreement with Libby and Lindsay (2010), Sponem and Lambert' (2016) study confirms that using the budget for evaluating performance is not a universal practice, and some organizations explicitly link their budget to strategy. Also, the yardstick, coercive and interactive styles of budgets all relate to different forms of "budgetary control" (i.e. the use of the budget to monitor results throughout the year and to evaluate performance at the end of the year); yet, sometimes, budgets are not used to control but play a role in defining strategy (the loose budget). 
In the sense, Hope and Fraser (2003) suggestthat budgets cannot be designated as a universal, fully standardized and stable set of tools with standardized use. More specifically, Sponem and Lambert (2016) also confirms that each of the five budget patterns plays a different role and is characterized by a different level of satisfaction. They also endorse the importance of participation and involvement of managers for budget satisfaction; emphasizing the importance of the content of discussions during budget negotiations. In this respect, it convinces that discussing budgets based on action plans and strategic objectives is more satisfying than discussing budgets only on a financial level. In this setting, combining budget satisfaction with the participation, involvement and consideration of action plans during budget negotiations suggests that individuals are more satisfied with the budget when it is used as a tool for discussion, exchange on business issues, or even socialization within the organization (Sponem and Lambert, 2016).

Bouquin (2010) referring eleven major budget design and use characteristics, categories budgeting process into three sequential stages: drafting stage (before action); steering stage (during action); and review and evaluation stage (after action) (cited by Sponem and Lambert, 2016).Reviewing literature Sponem and Lambert (2016) stated that in the drafting stage, organizations combine budgeting with strategy to varying degrees in budget negotiations; budget rigidity is considered a central characteristics of steering stage (defining budget revision as: possibility to change the initially set budgets and budget reforecast as: existence of a reforecast during the year; which could be combined in various ways); and in the review and evaluation stage, differences can be expected between the importance of budgeting for performance evaluation and importance of budgeting for determining rewards.

Upon identifying the gap in the literature, this study thus explores the patterns of budgeting relating to listed companies representing five different sectors in the Sri Lankan context, mainlyfocusing on its purposes, frequency of forecasting budgets, bases for formulating budget estimates, budget revision, and application of ABB.

\section{Findings and Discussions}

Patterns of budgeting practices may vary among sampled companies from one another within the industry and between industries, irrespective of their resemblance through manufacturing and manufacturing-related operations. 
Upon ascertaining characteristics of the sampled companies, this section continues to analyse and discuss the patterns of budgeting practices with respect to the following aspects whilst stressing associated similarities and differences among sectors.

\subsection{Characteristics of the sampled companies}

All companies in the sample deal with manufacturing and selling of different types of products for local and/or export markets. As illustrated in Table 3, out of 42 sampled companies, the majority is large size and the lesser is medium size, and the types of businesses are different among sectors. This study demarcates large and medium scale companies following 'National Policy Framework for Small and Medium Enterprises (SME) - 2015 (www.industry.gov.lk).

Table 3. Size of companies and types of businesses by industry sector

\begin{tabular}{|l|c|c|l|}
\hline \multirow{2}{*}{$\begin{array}{l}\text { Industry } \\
\text { sector }\end{array}$} & \multicolumn{2}{|c|}{ No. of } & \multicolumn{2}{|c|}{ Major products and types of businesses } \\
\cline { 2 - 3 } F \& B & Large & Medium & \multicolumn{1}{|c|}{$\begin{array}{l}\text { Food and beverage products (dairy products, fruit, coconut and organic } \\
\text { products, salt, poultry products; other consumer products }\end{array}$} \\
\hline CHEM & 2 & Size & Agro-inputs, chemicals, paints, bituminous products \\
\hline DVS & 5 & 0 & $\begin{array}{l}\text { Garments; blending and packing tea; baby items, cologne, soaps; other } \\
\text { consumer products; toothbrush and toothpaste etc. }\end{array}$ \\
\hline MNF & 10 & 8 & $\begin{array}{l}\text { Ceramic products; cables, wires, conductors; aluminium products; } \\
\text { refrigerators, washing machines, air conditioners, freezers, sewing } \\
\text { machines; rubber products; cement, wall plaster, concrete, tile adhesive, } \\
\text { flooring water proofing; pipes, show cases, partitions, ladders, sliding doors } \\
\text { and windows, roller shutters, curtain rails, channels etc. }\end{array}$ \\
\hline PLT & 8 & 0 & \begin{tabular}{l} 
Tea, rubber, coconuts, palm oil, cinnamon etc. \\
\hline
\end{tabular}
\end{tabular}

Considering accounting systems associated with budgeting practices, all companies are functioning with both MAS and Financial Accounting Systems (FAS). Out of 42 companies, 31 employed management accountants for the function while the restoperating with financial accountants; all of them are, however, carefullymonitored by finance executives.

\subsection{Patterns of budgeting practices of listed companies}

All companies in the sample apply budgeting in their routine planning and control functions. These findings are consistent with those of previous studies: Waweru et al. (2005), 98\% in South Africa; Hope and Fraser (1998), 99\% in Europe; Szychta (2002), 80\% in Poland; Abdel-Kader and Luther (2006), almost 
all companies in the UK; and Wijewardena and De Zoysa (1999), almost all companies in Australia and Japan.

\subsubsection{Budget components and frequency of forecasting budgets}

The results obtained pertaining to the forecast time period for budget preparation in relation to five major budget components are presented in Table 4 .

Table 4.The frequency of forecasting budgets for major components

\begin{tabular}{|lccccc|}
\hline \multicolumn{1}{|c}{ Budget components } & \multicolumn{5}{c}{ Forecast time period (\% of Companies applied) } \\
& Monthly & Quarterly & $\begin{array}{c}\text { Semi- } \\
\text { annually }\end{array}$ & Annually & $\begin{array}{c}\text { Beyond one } \\
\text { year }\end{array}$ \\
\hline Budgeted income statement (BIS) & 100 & 36 & 17 & 100 & 21 \\
Budgeted balance sheet (BBS) & 90 & 29 & 12 & 100 & 19 \\
Budgeted cash flow (BCF) & 95 & 29 & 12 & 100 & 17 \\
Operating budgets (OB) & 100 & 31 & 12 & 100 & 10 \\
Capital expenditure budgets (CEB) & 79 & 26 & 12 & 100 & 24 \\
$\quad$ Average Index & $\mathbf{9 3}$ & $\mathbf{3 0}$ & $\mathbf{1 3}$ & $\mathbf{1 0 0}$ & $\mathbf{1 8}$ \\
\hline
\end{tabular}

The findings reveals that basically, all companies $(100 \%)$ initially prepare annual budgets for all these components and then divide these into monthly and/or quarterly budgets according to their requirements. They all (100\%) prepare only BIS and OB monthly, as these two are typically more important for their routine planning and control functions than are others. They give less attention to monthly CEB (79\%): as some respondents commented, it is difficult to forecast CEB monthly basis, so instead they give more attention to monthly BCF and BBS, because these two are rather useful in managing business day-to-day. Relating to semiannual budgets, they pay the lowest attention to $(13 \%)$ in general, but give more importance to BIS (17\%) compared to other components, probably due to their greater concern about the impact of transactions on the income level of the company.

Companies are compelled to prepare quarterly budgets to an extent (30\%), because some companies make budget revisions quarterly whilst business processes are going on. Also, long-run budgets $(18 \%)$ are more useful than semi-annual budgets (13\%). In the long 
run, they normally prepare budgets for next three or five years, mostly in summary form, but detailed budgets only for the next first year beyond one year. In the long term, compared to other components, the highest attention goes to $\mathrm{CEB}(24 \%)$ due to its high practicality and usefulness, whilst lowest attention is on $\mathrm{OB}(10 \%)$, because it is rather difficult (and indeed useless) to prepare $\mathrm{OB}$ beyond one year in a changing business environment. But, in the longrun, $\mathrm{CEB}$ is rather useful compared to other components as it associated with a large amount of funds required in future. Among the industry sectors, there are no significance differences in the frequency of preparing budget components.

However, consideringthe nature of long term budgets, it identified differences among sectors to a certain extent.For examples, one in the F \& B sector prepares only summary budgets, forecasting sales and profit for next five years; one in CHEM sector prepares three year plan for all components except for OB; In the DVS sector, one multi-national company and one leading company prepare BIS, BBS and CEB budgets for three years and five years respectively. In the MNF sector, one prepares all budgets for three years: next first year on monthly basis and next second and third year on annual basis, and another one prepares all budgets for five years except for OB. In the PLT sector, two companies prepare all budgets for five years as summary estimates.

Similarly, Wijewardena and De Zoysa (1999) find that the budget components considered above were prepared by almost all companies in Australian and Japan, but the considerable difference between these two countries is that the balance sheet and capital expenditure budget are seen to be less popular in Japan. Somewhat deviating from the findings of this study, they reveal that annual budgets are the most popular in Australia as opposed to biannual budgets in Japan, and monthly budgets are at moderate level, while quarterly budgets seem to be less important in both Australia and Japan. Also, the least importance was given to long-run budgets, with figures of $4 \%$ in Japan and $15 \%$ in Australia. Thus, these findings confirm that there seems to be certain differences on the frequency of forecasting different budget components by companies/ sectors within the country and also among countries possibly due to their necessity, policies and interest of individual companies. 


\subsubsection{Budget revision and implementation}

Implementation of budgets with or without revision and the frequency of revision made by sectors are summarized in Table 5. companies). As evidenced from Table 3, F \& B sector shows tendency to produce consumer products so that they can revise budgets on monthly basis more easily than do others dealing with durable products i.e. MNF sector. Also, such a highest tendency $(100 \%)$ in the CHEM sector towards monthly revision may be attributed to its high level of apparent environmental uncertainty

Table5. Implementation of budgets with or without revision

\begin{tabular}{|lccccc|}
\hline Industry sector & \multicolumn{3}{c}{ Implementation of budgets with or without revision } & Total \\
& No revision & Revise monthly & Revise quarterly & Revise if needed & \\
\hline F \& B & 2 & 4 & 1 & 1 & 8 \\
CHEM & 0 & 3 & 0 & 0 & 3 \\
DVS & 3 & 1 & 1 & 0 & 5 \\
MNF & 11 & 2 & 5 & 0 & 18 \\
PLT & 2 & 1 & 4 & 1 & 8 \\
Total & 18 & 11 & 11 & 2 & 42 \\
Percentage ( \%) & 42.9 & 26.2 & 26.2 & 4.8 & 100 \\
\hline
\end{tabular}

The findings reveal that all companies discuss progress each month and each quarter at regular board meetings held monthly, however, budget revision takes place depending on their policies, necessity and applicability. In view of that, monthly/quarterly revision is at a moderate level $(26.2 \%+26.2 \%=$ $52.4 \%$ ) showing equal importance in each. There seems to be considerable differences among sectors with regards to nature of businesses as summarized in Table 3. Thus, patterns of budget revision can be analysed with regards to nature of businesses across sectors.

Among five sectors, monthly revision mostly relates to $\mathrm{F} \& \mathrm{~B}(50 \%$ of companies) and toCHEM (100\% of with agro- inputs and related products which exhibit greater impact of weather changes on sales. For examples; with regard to specific circumstances seemed in thebusiness, finance manager of one companyin the CHEM sector,dealing with fertilizer and agro-chemicals expressed their experience:

"We essentially require budget revisions, called 'situation based budget revision' each month due to weather changes. As the weather forecasts strongly affect sales, we normally prepare seasonal-based budgets. Due to unfavourable weather conditions, there would be drastic decline in sales in some 
periods. If we couldn't recover budgeted sales in a certain month, then we revise the budget, anticipating achieving targets in the next month, but it further depends on the weather conditions of the coming month too".

Of five sectors, quarterly revision mostly appears in both MNF (28\%) and PLT (50\%) sectors. Findings evidence that all in the MNF sector that are practicing with quarterly revision deal with durable products such as cements, cables, tiles, electric items. Considering PLT sector, the highest proportion $(50 \%)$ indicates quarterly revision probably due to its applicability and specific nature of businesses in the whole sector. Because it is difficult to makemonthly revision $(12.5 \%)$ for crops like tea, rubber, coconuts, and thus, of the sector, $25 \%$ experienced with no revision.Further, such practices appeared in the PLT sector may be attributed largely to the nature of markets they are dealing with; entirely depend on export markets, where making changesmonthlyfor budgeted sales is rather very difficult and impossible than those dealing with local markets.

It further reveals that, in general, the use of such budget revisions may be attributed to the level of apparent environmental uncertainty experienced in developing countries like Sri Lanka.
Waweru et al. (2005)present similar views, reasoning from environmental uncertainty that flexible budgeting is most widely adopted by South African companies $(68.7 \%)$ in view of the rapidly changing business environment. Similar situations can further be identified in studies such as Szychta (2002), with $74 \%$, in Poland, and Waweru et al. (2003), where $68 \%$ of companies in Kenya use flexible budgets.Accordingly, Waweru et al. (2005) also suggest that the high use of flexible budgets in South Africa may be attributed to the high levels of perceived environmental uncertainty experienced in developing countries.

As illustrated in Table 5, in contrast, $42.9 \%$ of respondents (majority representing MNF sector-11/18) of the present studyuse budgeting technique with no revision and thus agreed with the following sentiments:

"We do not make changes to initially prepared budgets because, in practice, we have no remarkable changes between actuals and related budgets. We believe that it seems to be a timeconsuming task and/or a no-value-added task. However, if any differences occurred, we can identify them with reasons at the monthly board meetings and so we take actions promptly if these deficiencies are controllable". 
Also, $60 \%$ of DVS sector experienced with no revision. Finance manager of a company in the DVS sector dealing with garments stated:

"We have no need to consider budget revisions because we do not entirely rely on budgets, and thus use budgets basically for financial planning, performance management and cost control purposes. In planning activities, we mostly use a monthly production plan, which is prepared based on orders placed, demand, style of the customers, employment and circumstances prevailing in the period, but this plan is not linked to the budget. Thus, more concentration is on customer needs of the period because as garments, the demand for them and fashion normally change within short periods of time".

Accordingly, findings realize that majority in both MNF (61\%) and DVS $(60 \%)$ sectors who are dealing with durable products practice budgeting as a tool of planning and control with no revision to initially prepared budgets. This trend may be largely attributed to the inability and needless of applying budget revision to durable products. Moreover, minority in both F \& B and PLT sectors $(25 \%$ representing each sector) experience with no revision, probably due to their policies and procedures. In this concern, however, the finance manager of a leading company for beer products in the F \& B sector stated that theyimplement budgets with no revision due to their nature of products and policies. In line with this, Waweru et al. (2005) pointed out that in the UK, as a developed countryexperiencing with a relatively stable economy, justified the widespread use of fixed budgets.

Also, 4.8\% respondents, signifying only in F\& B and PLT sectors, reported that they revise budgets (if needed) only if there appear to be considerable differences between actual and budgeted outcome in the past period considered. But this practice seems to be at a lower level owing $12.5 \%$ each by both sectors. In this respect, the respondent in $\mathrm{F}$ \&B sector mentioned that:

"We normally discuss the previous month's progress and present situation in the monthly board meetings and based on that ground we take decisions on how to coordinate with next month activities".

Supporting to this view, Abdel-Kader and Luther (2006) reveal that all most all companies in the UK use budgeting for planning and control, but a high 
proportion did not amend their budgets for changes in volume or other factors and thus, they work only with fixed budgets, applying 'what if' analysis fairly frequently.Also, most of respondents $(83 \%)$ in the UK identified budgeting as an important part of their long-term strategic planning. Supporting to this, Wijewardena and De Zoysa (1999) signposted that budgeting is considered as an equally important MA tool for planning and controlling product costs in Australia and Japan.

The above findings thus advocate that necessity and frequency of budget revision largely rely on the explicit nature of businesseswhich determine the nature of products, processes and markets (normally specified sector wise), and the policies and procedures of individual companies.

\subsubsection{Application of Activity-based budgeting (ABB)}

As illustrated in Table 6, adoption of ABB in the Sri Lankan context seems to be at moderate level (52.4), but another $11.9 \%$ has been given some consideration towards this and $9.5 \%$ intend to introduce $\mathrm{ABB}$ in future.In the sense, itshows rather high application compared to previous findings. For example, relating to developing countries i.e., Waweru et al. (2005) $-11.7 \%$ in South Africa, Joshi (2001) $-7 \%$ in India; and in developed countries, Abdel - Kader and Luther (2006) found that ABBwas considered as important or moderately important by $63 \%$ respondents in the UK, and only few $(19 \%)$ used it often or very often.

Table 6 Application of activity-based budgeting (ABB)

\begin{tabular}{|c|c|c|c|c|c|c|c|}
\hline \multirow{2}{*}{ Stages } & \multicolumn{6}{|c|}{ Number of Companies } & \multirow[t]{2}{*}{ Percentage } \\
\hline & F\&B & CHEM & DVS & MNF & PLT & Total & \\
\hline ABB has been introduced & 4 & 1 & 3 & 6 & 8 & 22 & 52.4 \\
\hline It is intended to introduce $\mathrm{ABB}$ & 0 & 0 & 2 & 2 & 0 & 4 & 9.5 \\
\hline $\begin{array}{l}\text { Some consideration has been } \\
\text { given to introduce } A B B \text { in future }\end{array}$ & 0 & 1 & 0 & 4 & 0 & 5 & 11.9 \\
\hline $\begin{array}{l}\text { A decision has not been taken to } \\
\text { introduce } A B B\end{array}$ & 3 & 0 & 0 & 3 & 0 & 6 & 14.3 \\
\hline No discussions so far & 1 & 1 & 0 & 3 & 0 & 5 & 11.9 \\
\hline Total & 8 & 3 & 5 & 18 & 8 & 42 & 100.0 \\
\hline
\end{tabular}


In view of sectors, a specific situation can be seen in the PLT sector reporting $100 \%$ application of $\mathrm{ABB}$ as of $A B C$,depending on their needs, applicability and curiosity. In the whole sector, manufacturing processes are going on at different estates spread throughout the country. In this setting, costs can easily be identified and managed in relating to activities taken place in those estates. Then, all in DVS sector have shown extensive commitment on ABB- $60 \%$ introduced and $40 \%$ intend to introduce in future. Attention given by $\mathrm{F} \& \mathrm{~B}$ sector is at Moderate level $(50 \%)$ whilst less attention shown by MNF sector (33 1/3\%) to implement ABB. Nevertheless, another $331 / 3$ in MNF sector $(2+4$ out of 18$)$ has given some consideration and intend to introduce the technique respectively. Moreover, inpercentage, the level of adoption of $\mathrm{ABB}$ by $\mathrm{CHEM}$ sector is somewhat similar to that of MNF sector.

Findings evidence that all companies who apply ABC (20 companies) representing five sectors unsurprisingly apply ABB too, as these two are mostly interrelated. Apart from the integration of $\mathrm{ABC}$ and $\mathrm{ABB}$, thisstudy further illustrates a tendency towards adoption of $\mathrm{ABB}(52.4 \%-22 / 42)$ rather than $\mathrm{ABC}$ $(47.6 \%$ - 20/42) on average. This suggests that Sri Lankan companies would rather concern themselves with budgeting than costing, being convinced of the importance of planning rather than control of business processes through costing systems.

This is further confirmed with the facts(see table 9) that budgeting seems to be the most important technique for all companies, irrespective of type of industry sector and/or of business, playing the biggest role for planning activities and a slightly lesser role forother functions i.e. coordination, control. Consistent with this finding, Abdel - Kader and Luther (2006) state that in the UK, $A B B$ is seen to be noticeably more important and frequently used than $\mathrm{ABC}$, supporting their general finding that 'budgeting is more valuable than costing'.

\subsubsection{Methods offorecasting sales}

In view of always/often use of following methods for forecasting sales, it realizes that almost all companies (95\%) use subjective estimates based on managerial experience, and statistical forecasting seems to be at above average level $(64 \%)$. Yet, market research is remarkably low (26\%) in Sri Lanka(see Table 7). These findings are consistent with those of Waweru et al. (2005), where $85 \%$ of respondents always/often used subjective methods. 
Table7. The pattern of forecasting sales using different methods

\begin{tabular}{|c|c|c|c|c|c|c|c|c|c|c|c|}
\hline \multirow[t]{2}{*}{ Technique } & \multicolumn{10}{|c|}{ Number of Companies and percentages } & \multirow[t]{2}{*}{ Rank } \\
\hline & (a) & $\%$ & (b) & $\%$ & (c) & $\%$ & (d) & $\%$ & (e) & $\%$ & \\
\hline $\begin{array}{l}\text { Statistical } \\
\text { forecasting }\end{array}$ & 15 & 35.7 & 12 & 28.6 & 4 & 9.5 & 2 & 4.8 & 9 & 21.4 & 2 \\
\hline Market research & 6 & 14.3 & 5 & 11.9 & 18 & 42.9 & 3 & 7.1 & 10 & 23.8 & 3 \\
\hline $\begin{array}{l}\text { Subjective } \\
\text { estimates-based on } \\
\text { staff experience }\end{array}$ & 30 & 71.4 & 10 & 23.8 & 0 & 0 & 1 & 2.4 & 1 & 2.4 & 1 \\
\hline
\end{tabular}

Notes: 1. (a) Always; (b) Often; (c) Sometimes; (d) Rarely; (e) Never

2. Ranking was based on values obtained by (always*3) $+($ often*2) $+($ sometimes $* 1)$

Of the respondents not undertaking market research, majority represent PLT sector (No-one in the PLT sector use it). Because they mostly deal with export markets and cannot identify their customers in the local market as they sell their brands through brokers (e.g., tea brokers, rubber brokers) so that market research might not be important in the industry. Instead, $75 \%$ in the sector always/often use statistical methods based on production targets estimated by estate managers, as their production is mostly equal to sales volume.

Further, one large company in the DVS sector stated that, as they deal only with the export market (the UK, the USA) for garment products, they have no need to undertake market research with regard to sales forecasts. However, this shows different views in relation to other companies/sectors: for example, a company in the CHEM sector that prepares seasonal budgets due to changes in weather conditions stated that a sister company in the group undertakes market research full time to identify demand for agricultural inputs and product related issues. They forecast sales using statistical forecasts, subjective experience and market research data.

Thus, these findings suggest that Sri Lankan companies mostly prefer to use subjective estimates based on experience, probably due to its simplicity, and thus meeting cost/benefit considerations. Also, irrespective of the limited use of statistical methods in South Africa, undoubtedly due to their sophistication and associated costs, this study confirms satisfactory usage of this 
technique in Sri Lanka. This trend might be due to the solid competition faced by Sri Lankan listed companies both in local and foreign markets. Companies pay less attention to market research, perhaps due to its inapplicability/ needless in certainsituations where substantial proportion/entire sales deal with the export market (i.e. Garments in DVS sector;PLT sector). Moreover, this trend may reinforce with the readiness of other sources in Sri Lanka for market information, some of which is publicly available sources.

\subsubsection{Bases considered in preparing operational budgets}

It appears a low application of zerobased budgeting (ZBB) (33\%) in Sri
Lanka; instead firms mostly use the previous year's actuals (81\%) as a base for preparing operational budgets, as shown in Table 8.

This is not consistent with MA literature, which indicates a high application of ZBB (58.8\%) in South Africa(Waweru et al., 2005). However, Szychta (2002) founds somewhat similar situation to the Sri Lankan context, in that $38 \%$ of companies use ZBB in Poland. Further, the moderate level application of Base 3 $(52 \%)$ in this study may be attributed to the application of $\mathrm{ABB}$ and $\mathrm{ABC}$ (which also appear at a moderate level as discussed in the previous section) by those companies.

Table 8. Bases used in preparing operational budgets

\begin{tabular}{|lccccccc|}
\hline \multicolumn{1}{|c}{ Bases } & \multicolumn{7}{c|}{ Number of Companies } \\
& F\&B & CHEM & DVS & MNF & PLT & Total & $\%$ \\
Base 1 - Previous years actuals & 8 & 3 & 5 & 13 & 5 & 34 & $\mathbf{8 0 . 9 5}$ \\
Base 2 - ZBB & 2 & 0 & 1 & 7 & 4 & 14 & $\mathbf{3 3 . 3 3}$ \\
$\begin{array}{l}\text { Base 3 - Different activities } \\
\text { (Activity based budgeting-ABB) }\end{array}$ & 5 & 1 & 4 & 7 & 5 & 22 & $\mathbf{5 2 . 3 8}$ \\
\hline
\end{tabular}

Considering industry sectors, the MNF (39\%) and PLT (50\%) sectors have shown a higher level of application of ZBB than others. This trend may be attributed to the nature of products these two sectors handle: for example, most in the MNF sector manufacture durable products that typically require $\mathrm{ZBB}$. Asagricultural products, the PLT sector usually confronts with changing weather conditions and changes in their production processes that require new 
budgets in a timely manner, and thus the PLT sector might show a greater application of ZBB compared to other sectors.

Most respondents use more than one technique at the same time to ensure the viability of budgets: for example, 15 respondents use Bases 1 and 3, six use Bases 1 and 2, and two use all Bases at once. Most respondents indicate that normally they also consider the previous year's actuals as a measure of applicability of budgets when in general they use the other two Bases for this function. Compared to other Bases, ZBB requires much more effort and time, so that meeting cost/benefit requirements might be a problem. However, to avoid deficiencies associated with $\mathrm{ZBB}$, some companies use it, combining it with either of the other two Bases: for example, six companies use ZBB with Base 1 and three use ZBB with Base 3, or rarely use both options together with ZBB (two companies). A similar situation (use of ZBB with other Bases) can be seen in the South African companies as reported by Waweru et al. (2005). Supportive of this view, Hope and Fraser (1998) also propose a move towards the adoption of ZBB in order to counter the deficiencies of incremental budgets.

\subsubsection{Purposes of budgeting}

The results indicate moderate/high importance relating to all purposes, as shown in Table 9.

Table 9. Importance of budgeting pertaining to different purposes

\begin{tabular}{|lccccc|}
\hline \multicolumn{1}{c}{ Purposes } & \multicolumn{7}{c}{ Number of Companies \& percentages } & \\
& High & $\%$ & Moderate & $\%$ & Rank \\
Planning activities & 39 & 92.9 & 3 & 7.1 & 1 \\
Communicating business activities & 23 & 54.8 & 19 & 45.2 & 6 \\
Coordinating activities & 34 & 81.0 & 8 & 19.0 & 2 \\
Allocating resources for day-to-day & 32 & 76.2 & 10 & 23.8 & 4 \\
operations & & & & & \\
Authorization & 22 & 52.4 & 20 & 47.6 & 7 \\
Control & 33 & 78.6 & 9 & 21.4 & 3 \\
Performance evaluation & 29 & 69.0 & 13 & 31.0 & 5 \\
Motivation & 21 & 50.0 & 21 & 50.0 & 8 \\
\hline
\end{tabular}

Notes: Ranking was based on values obtained by (high*3) + (moderate*2) 
It is shown that budgeting seems to be the most important technique for all companies, irrespective of type of industry sector and/or of business, playing the biggest role for planning activities and a slightly lesser role for coordination, control and orderly resource allocation functions. However, the least importance appears for motivation. These findings are somewhat different from those of Waweru et al. (2005), where budgeting plays a much greater role in controlling activities of organizations than in motivating managers, while planning is identified as the second important function.

In view of the above analysis and discussions, overall this study confirms that all companies practice budgeting mainly for planning, coordinating, control and resource allocation purposes. It seems certain differences on the popularity and frequency of forecasting various budget components by sectors. Annually (100\%), and monthly (93\%) budgets are more popular than quarterly (30\%), semiannually (13\%) and beyond one year (18\%) prepared budgets. The pattern applied is all companies initially prepare annual budgets for all components: budgeted income statement; budgeted balance sheet; budgeted cash flows; operating budgets and capital expenditure budgets, and then divide these into monthly and quarterly budgets according to their requirements.

All companies discuss progress monthly and quarterly at regular board meetings and revise budgets, as and when required, depending on their specific nature of businesses, environmental changes, necessity, applicability, policies and procedures of companies. All companies mostly use subjective estimates based on experience due to its simplicity, meeting cost/ benefit criterion. Yet, market research is remarkably low in Sri Lanka perhaps due to its inapplicability/ needless to companies dealing with the export market (i.e. PLT sector) and availability of other sources for market information. Concerning bases used for budget estimates, differences among sectors appear with greater application of ZBB by PLT sector than other sectors. Further, most companies use more than one base at once ensuring viability of budgets. Findings suggest that budgeting seems to be the most important technique for all companies irrespective of their sector playing the biggest role for planning than control of businesses. 


\section{Conclusions and implications of the study}

\subsection{Conclusions}

Sampled of 42 companies, representing five industry sectors engage in manufacturing and selling of different types of products for local and/or export markets. The majority (73.8\%) is large size and the rest denotes medium size companies. Budgeting seems to be an essential tool for all, demonstrating its significance mainly for planning, coordinating, control and resource allocation purposes.However, patterns of application of budgetingvary to a considerable extent in view of its certain aspects as discussed above, from one another within the industry and between industries. Such differences may be largely attributed to the nature of businesses, impact of environmental changes on business activities i.e. production and sales, markets served (local or foreign),policies, procedures, and specific circumstances that individual companies exercised. Thus, it suggests that these factors may have an impact on the patterns of budgeting practices adopted by individual companies/industry sectors.

All companies initially prepare annual budgets for all components considered and then divide these into monthly and/or quarterly budgets according to their requirements. Monthly basis BIS and $\mathrm{OB}$ are the most popular budgets among all, due to their greater importance for routine planning and control functions than are others (BBS, $\mathrm{BCF}$ and $\mathrm{CEB}$ ). Some companies are compelled to prepare quarterly budgets to an extent (30\%), as they make budget revisions quarterly whilst business processes are going on.In the long run, irrespective of immaterial differences prevailed amongst companies, it seems that they normally prepare budgets for next three or five years, mostly in summary form, but detailed budgets only for the next first year beyond one year. Compared to other components, the highest attention goes to CEB (24\%) due to its high practicality and usefulness in the long term, dealing with a large amount of funds required in future, whilst lowest attention is to OB $(10 \%)$, probably due to its difficultness and indeed pointlessness to prepare $\mathrm{OB}$ beyond one year in a changing business environment.

Even though all companies discuss progress each month and each quarter at regular board meetings held monthly, budget revision takes place depending on their policies, necessity and applicability to their own businesses. In view of necessity and frequency of budget revision, there seems to be considerable differences among sectors 
mainly due to their specific nature of businesses, policies and judgments of management. Monthly/quarterly revision is at a moderate level showing equal importance in each.It concludes that monthly revision is more suitable for companies producing consumer products (i.e. F \& B sector) than others dealing with durable products (i.e. MNF sector) and also for businesses facing high level of apparent environmental uncertainty with agro- inputs and related products (i.e. CHEM sector).

On the other hand, quarterly revision istypicallysuitable for businesses producing durable products (i.e. MNF sector) than others. Yet, majority in the sector $(11 / 18)$ exercise with no revisionlargely due to its inability and needless of applying budget revision to such durable products.Also, quarterly revision is more practical for businesses dealing with crops like tea, rubber, coconuts (i.e. PLT sector -50\%) probably due to its fitness to inherent nature of businesses. This, in turn, implies that monthly revision is rather not applicable for such businesses (PLT sector only $12.5 \%$ ). This inaptness further enriches by the fact that the markets those companies deals with: the export markets (PLT sector), where making revision monthly for sales is rather very difficult and impossible than those dealing with local markets.
Meanwhile, some are experiencing with no revision probably due to their specific nature of products and markets like garments, policies and opinions of management on the matter (i.e. PLT -25 $\%$; DVS - (60\%).It also suggests that 'seasonal-based budgets' and 'situation based budget revisions' are preferable for CHEM and PLT sectors to cater to demands for their products, as they are experiencing with high environmental uncertainty with agro-inputs and agricultural products due to weather changes. Findings thus concludes that there seems to be substantial differences amongst sectors relation to patterns of budget revision, so that necessity and frequency of budget revision largely rely on the explicit nature of businesses and accompanying situations that individual companies/sectors encountered, and policies, procedures and judgments of individual companies.

Contrary to less application shown in previous studies particularly in developing Countries (i.e.Waweru et al., 2005), overall this study shows moderate level application of $\mathrm{ABB}$. Nevertheless, findings confirm that besides the strange application of $\mathrm{ABB}$ in the PLT sector $(100 \%, 8 / 8$ companies)as of $\mathrm{ABC}$, conceivably depending on their needs, applicability and curiosity, in the Sri Lankan context its application seems to be at below 
average level (41\%, 14 out of 34 representing other four sectors). Conversely, in developedCountries, like the UK (Abdel-Kader and Luther, 2006)indicated rather extensive responsiveness to $\mathrm{ABB}$.Besides the inter-relation between application of $\mathrm{ABB}$ and $\mathrm{ABC}$, in agreement with Abdel-Kader and Luther (2006) it concludes that Sri Lankan companies would rather concern with budgeting than costing, being convinced of the importance of planning rather than control of business processes. This further confirmed with the factsdepicted in Table 9.

In forecasting sales, in consistent with Waweru et al. (2005) (85\%), the most popular technique $(95 \%)$ is 'subjective estimates based on managerial experience mainly due to its simplicity, and thus meeting cost/benefit considerations. Also, irrespective of the limited use of statistical methods in South Africa, this study confirms satisfactory usage of this technique $(64 \%)$ in Sri Lanka probably due to the solid competition faced by Sri Lankan listed companies both in local and foreign markets. In contrast, companies pay less attention to market research, undoubtedly due to its irrelevance for some companies who are dealing with export markets i.e.PLT sector; garments, and availability of other sources for market information.In contrast, some companies demonstrategreater importance engaging in full-time researchdue to its specific nature of businesses (i.e. CHEM sector dealing with agricultural products) as described in section 4.2.4.

Relating to bases used in preparing operational budgets it appears differences among sectors. The use of $\mathrm{ZBB}$ is largely reliant upon the nature of products; showing higher application by PLT and by MNF sectors for agricultural products and durable products respectively, than others. However, most respondents use more than one technique at the same time to ensure the viability of budgets and also to avoid deficiencies associated with ZBB which requires much more effort and time. It further concludes that most respondents consider the previous year's actuals as a measure of applicability of budgets. Given that purposes of budgeting, findings confirm that budgeting seems to be the most important technique for all companies, irrespective of type of industry sector and/or of business, playing the biggest role for planning activities and a slightly lesser role for control. These findings are somewhat different from those of Waweru et al. (2005). 
Findings suggest that patterns of budgeting practicesare determined by the management of companies to a considerable extent subject to the nature of businesses, impact of environmental changes on business activities i.e. production and sales, nature of markets served (local or foreign), policies, procedures, and specific circumstances that individual companies exercised. In the sense, there appear substantial differences within the industry and between industries in view of patterns of application of budgeting as a tool for planning and control of business activities. Here, it suggests, agreeing with Trimisiu Tunji(2013), that in dealing with budgeting as a continuous management activity for planning and control of businesses, companies should adapt to changes in the dynamic business environment by applying the most appropriate patterns of budgeting so that enabling them to achieve intended purposes more precisely.

\subsection{Implication of the Study}

This study provides an understanding on different patterns or options available in applying budgeting techniques for different types of businesses operating under different organizational/ industrial contextual influences and social structural influences. In turn, it provides knowledge on nonapplicability of certain patterns of budgeting for particular companies / industry sectors as far as considering their inherent nature of businesses and associated features and conditions. Accordingly, this research provides insight into the importance of exploring the appropriateness of certain aspects of budgeting, patterns of applying those aspects for particular companies / industry sectors.

Moreover, this study provides understanding on the application of the MMR approach in MA research. This helps researchers understand means of presenting, analysing and interpreting both quantitative and qualitative data more effectively in the context of MMR design. It also provides insights to researchers in determining how and at which point of interface to integrate core and supplemental components properly, to obtain desired outcome in terms of meaningful interpretations and findings in the context of MMR design.

In summary, the study makes a considerable contribution to the empirical literature, to knowledge on budgeting practices and on the application of MMR design for MA research. It also provide insights into business entities and policy makers with directions, evidence and justifications, 
on application of budgeting technique appropriately for different types of businesses operating under different organizational/ industrial contextual influences and social structural influences. Overall, this study provides directions to scholars with required evidence and justifications to undertake further research on the phenomena under consideration.

\section{References}

Abdel-Kader, M., \& Luther, R. (2006). Management accounting practices in the British food and drink Industry British Food Journal, 108 (5), 336-357.

Barasa, E. W., Cleary, S., Molyneux, S., and English, M. (2017). Setting healthcare priorities: a description and evaluation of the budgeting and planning process in county hospitals in Kenya, Health Policy and Planning, 32, 329-337.

Bryman, A., \& Bell, E. (2007). Business Research Methods, (2nd ed.), Oxford University Press, New York.

Chenhall, R. H.,\&Langfield-Smith, K. (1998). Adoption and benefits of management accounting practices: an Australian study, Management Accounting Research, 9(1), 1-19.

Herath, S. K., \&Indrani, M. W. (2007). Budgeting as a Competitive Advantage: Evidence from Sri Lanka, Journal of American Academy of Business, 11(1), 79-91.
Hope, J.,\& Fraser, R. (1998), Beyong budgeting, breaking through the barrier to the third wave, Articles of Merit, International Federation of Accountants, 3-8.

Hope, J., and Fraser, R. (2003). Beyond budgeting: How managers can break free from the annual performance trap, Harvard Business Press.

Horngren C. T., Sundem, G. L., Stratton, W. O., Burgstahler, D. \&Schatzberg, J. (2008). Introduction to Management Accounting. (14th Ed.), New Jersey: Pearson Prentice Hall.

Joshi, P. L. (2001). The international diffusion of new management accounting practices: the case of India, Journal of International Accounting, Auditing \& Taxation, 10(1), 85- 109.

Libby, T., and Lindsay R. M. (2010). Beyond budgeting or budgeting reconsidered? A survey of NorthAmerican budgeting practice, Management Accounting Research, 21, 56-75.

Morse, J. M. (2010). Procedures and practice of mixed method design: Maintaining control, rigor, and complexity, Sage Handbook of Mixed Methods in Social \&Behavioral Research, (2nd ed). Thousand Oaks: Sage: 339-353.

National Policy Framework for Small and Medium Enterprises (SME)' in Sri Lanka (2015)www.industry.gov.lk

Onwuegbuzie, A. J., and Collins, K. M. T. (2007). A Typology of Mixed Methods Sampling Designs in Social Science 
Research, The Qualitative Report, 12 (2), 281-316.

Onyiah, I. A., Ezeamama, N. C. Ugwu, J. N., \&Mgbodile, C. C. (2016). Nigerian Budget Implementation and Control Reforms: Tool for Macro Economic Growth, British Journal of Economics, Management \& Trade,11(2), 1-13.

Scott, G. K., and Enu-Kwesi, F. (2018). Role of Budgeting Practices in Service Delivery in the Public Sector: A Study of District Assemblies in Ghana, Human Resource Management Research, 8(2): 23-33

Segun, A., \&Olamide, F.T. (2009). The Global Debate on Budgeting: Empirical Evidence from Nigeria, Business Management Review, 1(13), 1-13.

Senoo, T. (2018). Budgeting Patterns in Japanese Companies and their Relationship with Exploration and Exploitation: An Exploratory Study, Journal of Japanese Management, 3 (1), 1-21.

Sponem, S., and Lambert, C. (2016). Exploring Differences in Budget characteristics, Role, and Satisfaction: A Configurational Approach, Management Accounting Research, 30, 47-61.

Sulaiman, M. B.,Ahmad, N. N. N.,\&Alwi, N. (2004). Management accounting practices in selected Asian countries: A review of the literature, Managerial Auditing Journal, 19(4), 493-508.

Szychta, A. (2002). The Scope of Application of Management accounting methods in Polish enterprises,
Management Accounting Research, 13, 401-418.

TrimisiuTunji, S. (2013). The Impact of Budgeting and Budgetary Control on the Performance of Manufacturing Company in Nigeria, Journal of Business Management \& Social Sciences Research 2(12), 8-16.

Tuanmat, T.Z., \& Smith, M. (2011). Changes in management accounting practices in Malaysia, Asian Review of Accounting, 19 (3), 221 -242.

Veal, A.J. (2005). Business Research Methods: A Managerial Approach, (2nd ed.), Pearson Education Australia, NSW.

Waweru, N. M.,Hoque, Z. \& Uliana, E. (2005). A survey of management accounting practices in South Africa, International journal of accounting, auditing and performance evaluation, 2(3), 226-263.

Wijewardena, H., \& De Zoysa, A. (1999). A comparative analysis of management accounting practices in Australia and Japan: An empirical investigation, The International Journal of Accounting34(1), 49-70. 